\title{
VYRŲ IR MOTERŲ NUGAROS SKAUSMO IR STUBURO PASLANKUMO KITIMAS TAIKANT KINEZIVYTURAVIMĄ
}

\author{
Rasa Bacevičienè $\dot{\mathbf{1}}^{\mathbf{1}}$ Laura Janušoniené $\dot{\mathbf{}}^{\mathbf{1}}$, Milda Gintilienè ${ }^{2}$ \\ ${ }^{1}$ Panevéżio kolegija, ${ }^{2}$ Kauno kolegija
}

Raktažodžiai: nugaros skausmas, stuburo paslankumas, kinezivyturavimas (kineziteipavimas).

\begin{abstract}
Santrauka
Dažniausiai pasitaikančiam juosmeninès stuburo dalies skausmui gydyti taikomas alternatyvus metodas - kinezivyturavimas. Šis metodas, veikdamas fiziologinius mechanizmus, atkuria teisingą raumens funkciją, gerina kraujo ir limfos tekejimą, mažina skausmą, per propriorecepciją koreguoja sąnarių padèti, atstato teisingą raumens funkciją.

Tyrimo tikslas buvo nustatyti vyru ir moteru juosmeninės stuburo dalies skausmo ir paslankumo pokyčius taikant kinezivyturavimą. Tyrime dalyvavo 10 pacientų, kurių amžius 46,1 $\pm 4,95$ m, jaučiančių juosmeninị stuburo dalies skausmą. Visiems tiriamiesiems radiologinių tyrimų metu buvo nustatyta L5-S1 tarpslankstelinio disko išvarža. Vertintas skausmas kas 4 valandos VAS skale bei stuburo paslankumas prieš ir po kinezivyturavimo. Kinezivyturavimui naudotas K-Active dvi $20 \mathrm{~cm}$ ilgio ir $5 \mathrm{~cm}$ pločio kinezivyturo juostelès.

Rezultatai parodè, kad kinezivyturavimas padidino juosmeninès stuburo dalies paslankumą, kurio poveikis moterims buvo didesnis nei vyrams bei sumažino juosmeninès stuburo dalies skausmą praejjus 20 val. po kinezivyturo užklijavimo, o ryškiausias ir ilgiausiai trunkantis skausmo sumažejimas buvo stebimas 44-56 val., kuris moterims buvo didesnis nei vyrams.
\end{abstract}

\section{Ivadas}

Juosmeninès stuburo dalies skausmas yra vienas iš dažniausiai pasitaikančių sveikatos sutrikimų, kuris sumažina darbingumą, kartu reikalaudamas ir nemažų materialinių sąnaudų jo šalinimui $[1,14,18]$. Besikartojantis juosmeninès stuburo dalies skausmas sumažina stuburo mobilumą, blogina gyvenimo kokybę $[1,7,14]$. Nors kartą per metus nugaros skausmu skundžiasi apie $42 \%$ žmonių $[2,14]$, bent kartą gyvenime skausmą patiria apie 75 proc. gyventojų [3]. Didžioji dalis ūmių nugaros skausmų pranyksta per 1-3 mènesius, tačiau apie 15 proc. pacientu jaučia skausmą vienerius metus nuo jo pasireiškimo pradžios $[1,14]$, todèl reikia rasti efektyvų šios problemos gydymo būdą [3].Nugaros skausmo gydymui taikomi iprasti gydymo metodai: kineziterapija, fizioterapija, manualinè terapija, ịvairūs tepalai $[7,14]$. Laipsniškai vystantis technologijoms ir vis plačiau pritaikant naujoves gydymo srityje, ieškoma vis naujų nugaros skausmo gydymo metodų, kurie užkirstų kelią atsirasti ir progresuoti kaulų - raumenų sistemos ligoms $[7,17]$. Todèl kaip alternatyvi ir papildoma gydymo priemonè buvo sukurtas kinezivyturavimas. $1970 \mathrm{~m}$. Kenzo Kase sukūrè elastingą juostą, kurios struktūra buvo panaši ị odą ir pavadino Kinesio Tapel [17]. Kinezivyturavimo metodas sukurtas remiantis hipoteze, kad raumenu bei sausgyslių struktūrų funkcijoms pagerinti, neribodamas judesio amplitudès, gali padèti išorinis komponentas $[1,17,18]$.Kinezivyturas yra plona ir elastinga juosta, kuri gali išsitempti nuo $40 \%$ iki $60 \%$ pradinio savo ilgio ir suteikia pilną judesio amplitudę $[1,11,17,18]$. Pastaraisiais metais įrodyti keli kinezivyturavimo fiziologiniai efektai $[1,12,14,17,18]$ : kinezivyturas atkuria teisingą raumens funkciją, kuri buvo raumens silpninimo priežastis [17]; kinezivyturas pakeldamas odą padidina tarpus tarp odos ir raumens bei kitų audinių, todèl pagereja kraujo ir limfos apytaka, turinti reikšmès raumens ir fascijos funkcijoms [5]; kinezivyturas, veikdamas per odą, stimuliuoja odos mechanoreceptorius toje vietoje, kurioje jis yra užklijuotas. Šių receptorių dirginimą ir nervinio impulso atsiradimą sukelia mechaninè odos apkrova, kuriai priskiriamas lietimas, spaudimas, vibracija, tempimas ir gnybimas [18]. Dirginant odos mechanoreceptorius sukeliama depoliarizacija ir veikimo potencialas, kuris aferentais siunčiamas ị centrinę nervų sistemą. Kinezivyturavimas sukelia odos spaudimą ir tempimą, dèl to dirginami mechanoreceptoriai sąlygoja fiziologinius šios srities pokyčius ir minkštujų audinių plastiškumo padidejjimą, koreguoja sąnarių padètį [1,17].

Remiantis mokslininkų patvirtinimais apie kinezivytu- 
ravimo būdo veiksmingumą mažinant skausmą $[13,15]$ ir didinant judesių amplitudę [16,12,17], galime teigti, kad kinezivyturavimas yra tinkama priemonè juosmeninès stuburo dalies skausmo mažinimui bei mobilumui didinti. Dèl vis didejjančio kinezivyturavimo panaudojimo klinikinejje praktikoje yra būtina tirti šio metodo naudą ir suvienodinti šios technikos standartus remiantis moksliniais tyrimais.

Mūsų tyrimo tikslas - nustatyti vyrų ir moterų juosmeninès stuburo dalies skausmo ir paslankumo pokyčius taikant kinezivyturavimą.

\section{Metodika ir organizavimas}

Tyrime dalyvavo 10 pacientų, kurių amžius $46,1 \pm 4,95$ m, 5 moterys (amžius 47,2 $\pm 3,7$ ) ir 5 vyrai (amžius 45 $\pm 6,2$ ), jaučiančiu juosmeninị stuburo dalies skausmą. Visiems tiriamiesiems radiologinių tyrimų metu buvo nustatyta L5-S1 tarpslankstelinio disko išvarža. Tiriamujų charakteristikos pateiktos 1 lenteleje

Tiriamiesiems iki dalyvavimo tyrime niekada nebuvo taikytas kinezivyturavimas, todèl visiems buvo suteikta informacija apie kinezivyturavimo veikimo principą ir atsakyta ị visus klausimus, tačiau nepaminètas kinezivyturavimo poveikis, siekiant išvengti placebo efekto vertinant jaučiamo skausmo stiprumą.Juosmeninès stuburo dalies skausmas vertintas modifikuota vizualine analogine skausmo skale (VAS) balais nuo 0 (skausmo nèra) iki 10 (nepakeliamas skausmas).

1 lentelè. Tiriamụjų amžiaus, ūgio, svorio ir KMI vidutinės reikšmės

\begin{tabular}{|c|c|c|c|c|}
\hline Rytis & $\begin{array}{l}\text { Amžius ( } \bar{X}_{ \pm} \\
\text {SD), metai }\end{array}$ & 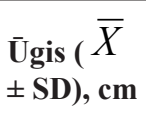 & $\begin{array}{l}\text { Svoris ( } \bar{X}_{ \pm} \\
\text {SD), kg }\end{array}$ & $\begin{array}{l}\text { KMI ( } \bar{X}_{ \pm} \\
\text {SD) }\end{array}$ \\
\hline Moterys $(\mathrm{n}=5)$ & $47,2 \pm 3,7$ & $\begin{array}{l}165,2 \pm \\
5,4\end{array}$ & $64,2 \pm 8,58$ & $23,6 \pm 3,7$ \\
\hline Vyrai $(\mathrm{n}=5)$ & $45 \pm 6,2$ & $\begin{array}{c}176,8 \pm \\
8,11\end{array}$ & $79,2 \pm 10,85$ & $25,2 \pm 2,1$ \\
\hline $\begin{array}{l}\text { Visi tiriamieji } \\
(\mathrm{n}=10)\end{array}$ & $46,1 \pm 4,95$ & $171 \pm 8,92$ & $71,7 \pm 12,15$ & $24,4 \pm 3,0$ \\
\hline
\end{tabular}

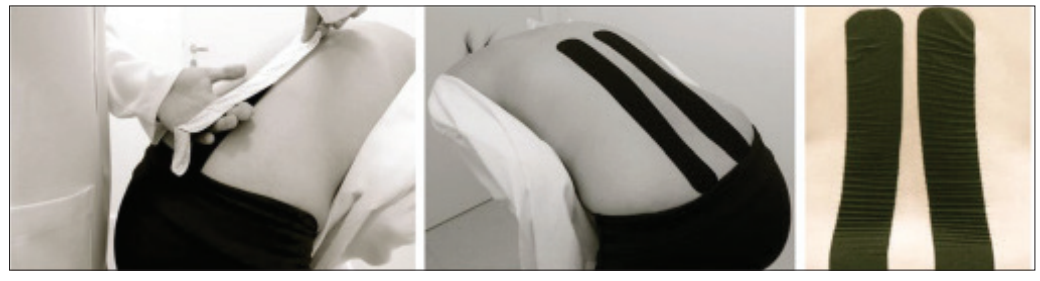

1 pav. Kinezivyturo klijavimo metodika
Tiriamujų juosmeninès stuburo dalies paslankumas vertintas naudojant modifikuotą Šobero testą (Karnath, 2003). Paslankumas vertintas tris kartus ir iš gautų rodiklių apskaičiuotas vidurkis registruojamas tyrimo protokole.

Kinezivyturavimui naudotas Japonijoje pagamintas KActive kinezivyturas. Remiantis Paoloni ir kt. (2011) atliktu tyrimu, pasirinktos dvi $20 \mathrm{~cm}$ ilgio ir $5 \mathrm{~cm}$ pločio kinezivyturo juostelès. Jos buvo klijuojamos atsižvelgiant ị Kase ir kt. (2003) pateiktus kinezivyturo klijavimo metodus (1 pav.).Vyturuojamas kūno plotas buvo švarus, be plaukų. Kinezivyturas buvo išmatuojamas, kai juosmeninè stuburo dalis buvo visiškai sulenkta. Pirmieji kinezivyturo 4-5 centimetrai buvo atsargiai atplèšiami nuo apsauginès juostelès ir bazė buvo klijuojama šalia kryžkaulio neutralioje padètyje. Toliau klijuojant kinezivyturą, pacientų buvo prašoma pilnai susilenkti per juosmeninę stuburo dali. Galutiniai 4-5 centimetrai kinezivyturo buvo užklijuojami ne ant ištemptos odos. Toks pat užklijavimo metodas buvo atliekamas ir kitoje stuburo pusèje. Kiekviena juostelè buvo klijuojama su 25 proc. ištempimu ant nugaros tiesiamojo raumens pilvelio. Užklijuotas kinezivyturas buvo patrinamas rankomis keletą kartų, kad sušiltų ir pagerètų sukibimas su oda.

Ivertinus tiriamujjų nugaros skausmą ir išmatavus stuburo juosmeninès dalies paslankumą, buvo užklijuojamas kinezivyturas. Vèliau, kiekvienas tiriamasis individualiai, kas keturias valandas (iki 56 val. skaičiuojant nuo vyturo užklijavimo laiko) vertino skausmą užrašydamas iš anksto tyrèjų sudarytoje lentelèje. Po 56 val. buvo nuplešiamas kinezivyturas ir atliekami pakartotinai skausmo ir paslankumo matavimai (2 pav.). Jie buvo atliekami praejus 5 min. po kinezivyturo nuplèšimo, siekiant išvengti klaidingų rezultatų dèl odos ir raumens reakcijos ị šią procedūrą.Visi tiriamieji buvo stacionare besigydantys pacientai, kuriems nuo pirmadienio iki penktadienio buvo taikomas masažas, fizioterapija ir grupine kineziterapija. Siekiant tyrimo objektyvumo, pirmas testavimas atliktas penktadieni po pietų. Iki pirmadienio ryto skausmą vertindavo tiriamieji individualiai, pirmadienio ryte, nuėmus vyturą, atliekamas antras testavimas.

Gautų tyrimo duomenų analizė atlikta naudojant SPSS programą. Paslankumas vertintas ir lyginti rezultatai tarp prieš ir po kinezivyturavimo bei lyginami tarp vyru ir moterų. Skausmo vertinimas ir lyginamoji analizè atlikta tarp kiekvieno matavimo. Skirtumai buvo laikomi statistiškai reikšmingais, kai $\mathrm{p}<0,05$. 


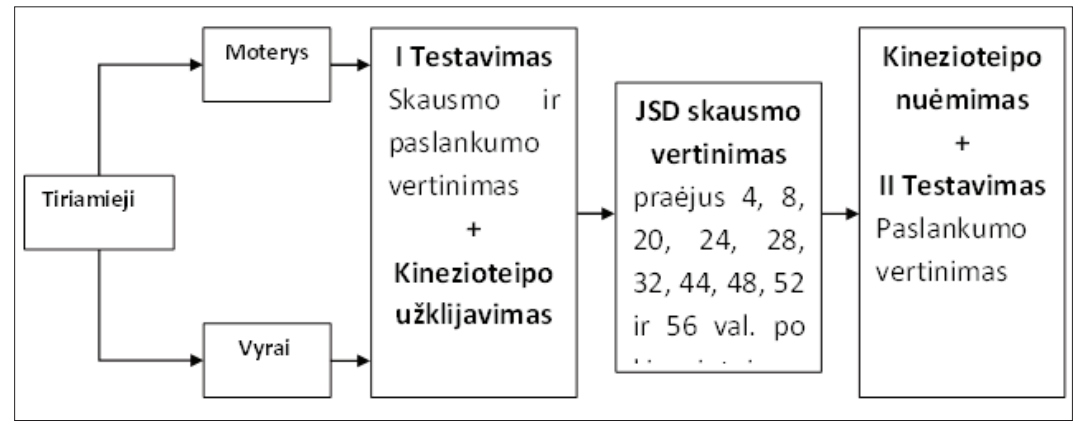

2 pav. Tyrimo protokolas

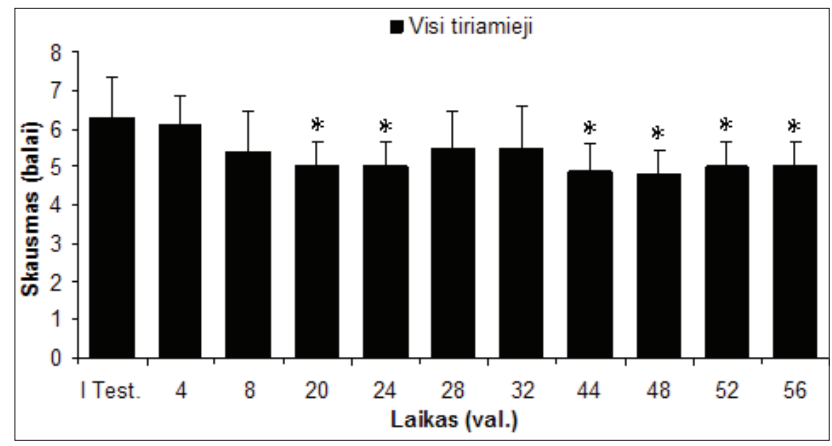

3 pav. Tiriamujų juosmeninès stuburo dalies skausmo kitimas po kinezivyturavimo per 56 val.

$*_{-}$skirtumas patikimas lyginant su pradine reikšme, kai p<0,05

\section{Rezultatai}

Tyrimo rezultatai parodè, kad kinezivyturavimas sumažino juosmeninès stuburo dalies skausmą (3 pav.). Skausmo mažèjimas stebimas ne iš karto po kinezivyturavimo, bet praejjus tik 8 valandom, o reikšmingas pokytis užregistruotas tik praejjus 20 valandų ir siekè $5 \pm 0,67$ balus. Pradinè skausmo reikšmè buvo $6,3 \pm 1,06$ balo.

Per kitas aštuonias valandas skausmas nežymiai didèjo, tačiau dar po aštuonių valandų, t.y. 44 val. nuo tyrimo pradžios, registruotas ženklus skausmo sumažèjimas, kuris siekè $4,9 \pm 0,74$ balo $(\mathrm{p}<0,05)$ ir tęsèsi iki tyrimo pabaigos. Skausmas po 48 val. sieké $4,8 \pm 0,63$ balo, po 52 val. $-5 \pm 0,67$ balo ir po $56 \mathrm{val}-5 \pm 0,67$ balo $(\mathrm{p}<0,05)$.

Analizuodami juosmeninès stuburo dalies skausmo kitimą tarp vyrų ir moterų grupių, nustatėme, kad vyrams skausmas kito nežymiai ir reikšmingo pokyčio tarp matavimų nenustatyta (4 pav.). Praejus 56 val. po kinezivyturavimo vyrų juosmeninès dalies skausmas sumažejo nuo pradinès $6,2 \pm 1,3$ balo reikšmès tik iki $5,2 \pm 0,45$ balo ( $p>0,05)$. İdomu ir tai, kad vyrams po 4 valandų nuo kinezivyturavimo pradžios skausmas ne tik kad nemažèjo, tačiau net padidejo $(p>0,05)$.Vèliau vyrų juosmeninès stuburo dalies skausmo kitimo kreivẻ buvo panaši ị visų tiriamųjų rodi- klių kaitą ir reikšmingų pokyčių tarp rezultatų nenustatyta.

Moterų juosmeninès stuburo dalies skausmo kreivé, kitaip nei vyrų, palaipsniui mažejo ir praejjus 20 val. po kinezivyturavimo nuo pradinès $6,4 \pm 0,89$ balo reikšmès sumažèjo iki $4,8 \pm 0,84$ balo $(\mathrm{p}<0,05)$. Reikšmingas ir ilgiausiai trunkantis juosmeninès dalies skausmo pokytis buvo stebimas jau nuo 44 val., kuris siekè $4,4 \pm 0,55$ balo, 48 val. $-4,4 \pm 0,55$ balo, 52 val. $-4,8 \pm 0,84$ balo ir 56 val $-4,8 \pm 0,84$ balo $(\mathrm{p}<0,05)$. I testavimo metu ir praejjus 56 val. po kinezivyturavimo reikšmingo skirtumo tarp vyrų ir moterų juosmeninès stuburo dalies skausmo vidutinio stiprumo nenustatyta.

Išanalizavus tyrimo duomenis nustatyta, kad moterų vidutinis JSD paslankumas I testavimo metu buvo $19,80 \pm 0,76 \mathrm{~cm}$, vyru $-20,50 \pm 1,27 \mathrm{~cm}$, o bendras visų tiriamuјu $-20,15 \pm 1,06 \mathrm{~cm}$ (13 pav.). I testavimo metu skirtumo tarp vyrų ir moteru vidutinio JSD paslankumo nenustatyta $(\mathrm{p}>0,05)$.

II testavimo metu nustatyta, kad moterų vidutinis JSD

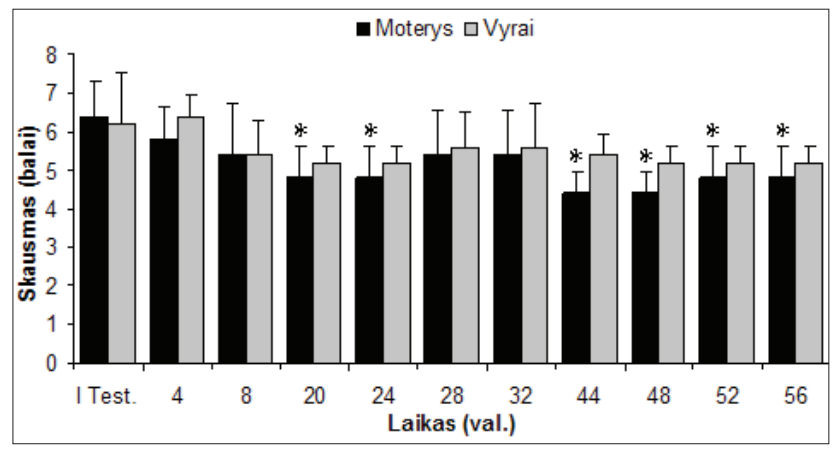

4 pav. Moterų ir vyrų juosmeninès stuburo dalies skausmo kitimas po kinezivyturavimo per 56 val.

*-skirtumas patikimas lyginant su pradine reikšme, kai p<0,05

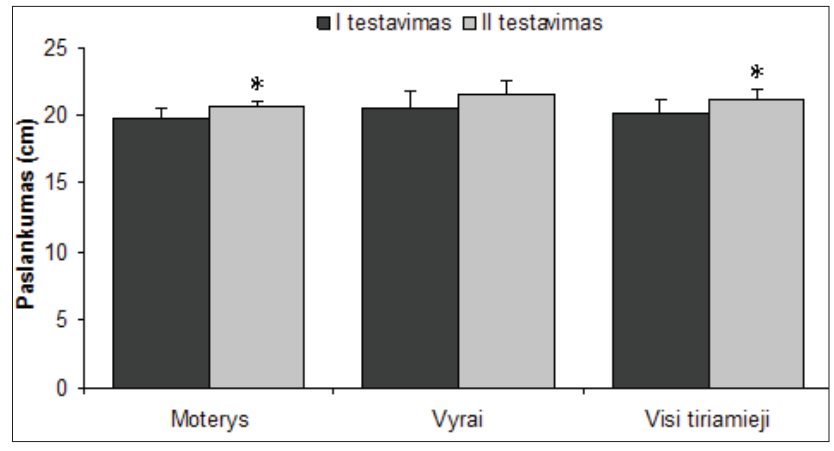

5 pav. Moterų ir vyrų I ir II testavimo juosmeninės stuburo dalies paslankumas

*-skirtumas tarp I ir II testavimo patikimas, kai p<0,05 
paslankumas padidèjo $(\mathrm{p}<0,05)$ iki $20,70 \pm 0,27 \mathrm{~cm}$. Vyru vidutinis JSD paslankumas padidejo iki $21,50 \pm 1,00 \mathrm{~cm}$, tačiau lyginant su I testavimo rezultatu skirtumas statistiškai nereikšmingas $(\mathrm{p}>0,05)$. Bendras visų tiriamujų vidutinis JSD paslankumas padidejo $(p<0,05)$ iki $21,10 \pm 0,81 \mathrm{~cm}$. II testavimo metu skirtumo tarp vyrų ir moterų vidutinio JSD paslankumo nenustatyta $(\mathrm{p}>0,05)$.

\section{Aptarimas}

Tyrimo rezultatai parodè, kad skausmas reikšmingai sumažèjo po 20 val. nuo kinezivyturavimo pradžios ir vèliau per paskutines $44-56$ val. nedidèjo. Kinezivyturavimo įtaką skausmo mažinimui pažymi ir kiti mokslininkai $[1,10$ $15,18]$. Pastarujų tyrimuose skausmo mažèjimas registruotas nuo 2 iki 4 savaičių. Tai ženkliai ilgesnis laikas nei mūsų atliktame tyrime. Tačiau kiti mokslininkai [17] taip pat nustatè reikšmingą skausmo mažèjimą bei raumenų jègos didejjimą per $24-48$ val. nuo vyturavimo pradžios. Be skausmo dydžio mažèjimo vyturuojant, mokslininkai nustatė, kad kartu mažeja ir skausmo intensyvumas $[7,16]$ bei gerejja ir juosmens raumenų ištvermé (Castro - Sanchez et al., 2012; Paolini et al., 2011). [1,10].

Tikslus raumenų skausmo mažejjimo mechanizmas iki galo nèra aiškus $[11,12]$, tačiau mokslininkai kelia hipotezę, kad skausmo jutimas yra netikslus nervinio impulso plitimas ị centrinę nervų sistemą, kurị ištaiso kinezivyturas $[1,16]$. Per didelè priestuburinių raumenų aktyvacija sukelia jų hipertrofiją [9], o užsitęsus šiam procesui, raumenys yra varginami. Pertemptas raumuo sąlygoja skausmo atsiradimą bei stimuliuoja Goldžio receptorius, kurie perduoda nervinio impulso plitimą i centrinę nervų sistemą. Kinezivyturas atpalaiduoja raumenį, sumažindamas Godžio receptorių aktyvumą ir prasideda neuronų aktyvacijos slopinimas $[1,16,17]$. Vyturuojant atsiradusi odos deformacija stimuliuoja odos mechanoreceptorius. Ši aktyvacija sukelia vietinę depoliarizaciją ir nerviniai impulsai aferentinèmis skaidulomis keliauja ị centrinę nervų sistemą $[13,16]$. Skausmo moduliacija pagal „vartų valdymo teoriją“ yra tas paaiškinimas dèl kinezivyturavimo poveikio mažinant skausmą.

Analizuodami vyrų ir moterų juosmeninės stuburo dalies skausmo pokytị taikant kinezivyturavimą, nustateme, kad moterims skausmas reikšmingai mažèjo daugiau nei vyrams. Manome, tam didelès reikšmès turejjo vyrams būdingas žemesnis nei moterims skausmo slenkstis. Mokslininkai nurodo [13], kad skausmo yra ne tik skirtingos ribos, tačiau jis siejasi su lytimi bei amžiumi. Reikia paminèti, kad skirtingus skausmo pokyčius po kinezivyturo užklijavimo mokslininkai gauna ir dèl galimo skirtingo kinezivyturo ištempimo klijuojant bei skirtingo vyturo ilgio $[16,17]$.
Kinezivyturavimo poveikį paslankumui nustatę mokslininkai [1,16-18] nurodo, kad dèl vyturavimo gerèja raumenu aktyvacija, o tai ir nulemia geresnę judesių amplitudę. Mes nustatėme, kad kinezivyturavimas reikšmingai padidino stuburo paslankumą po 56 val., kuris, kaip ir skausmas, moterims reikšmingai buvo didesnis nei vyrams. Yoshida ir Kahanov (2007) taip pat nustate ir šoninius stuburo judesių amplitudès didejjimus, kuriuos aiškina kinezivyturo per odą poveikiu: pakeldamas odą kinezivyturas padidina tarpus tarp odos ir raumens bei kitų audinių, todèl pagerejja kraujo ir limfos apytaka, turinti reikšmès raumens ir fascijos funkcijoms [8]. Mokslininkai nurodo [1], kad stuburo amplitudès vyturuojant gali kisti ir nereikšmingai dèl skausmo, kuris riboja judesius. Tačiau daugelis autorių $[5,16,17]$. nurodo, kad kinezivyturavimo poveikis priklauso nuo užklijuotų ant odos juostų skaičiaus ir formos, nes kai keičiasi impulsacija, didejja susitraukime dalyvaujančių motorinių vienetų raumenyje skaičius [5], koreguojama raumenų funkcija, atsiranda geresnis ryšys tarp fascijų ir kitų audinių, kinta propriorecepcija, kartu koreguojama laikysena bei judẻjimas [15].

Mūsų tyrimo rezultatai parodè, kad kinezivyturavimas sumažino juosmeninès stuburo dalies skausmą ir pagerino stuburo paslankumą. Todèl manytina, kad kinezivyturavimas yra tinkamas metodas, galintis sumažinti skausmą per gana trumpą laiką bei pagerinantis paslankumą.

\section{Išvados}

1. Kinezivyturavimas padidino juosmeninès stuburo dalies paslankumą, kurio poveikis moterims buvo didesnis nei vyrams.

2. Kinezivyturavimas sumažino juosmeninès stuburo dalies skausmą praejus 20 val. po kinezivyturo užklijavimo, o ryškiausias ir ilgiausiai trunkantis skausmo sumažèjimas buvo stebimas 44-56 val., kuris moterims buvo didesnis nei vyrams.

\section{Literatūra}

1. Castro-Sanchez AM, Lara-Palomo IC, Mataran-Penarrocha GA, Fernandez Sanchez M, Sanchez-Labraca N, Arroyo-Morales $\mathrm{M}$. Kinesio Taping reduces disability and pain slightly in chronic non-specific low back pain: a randomised trial. J Physiother 2012;58(2):89-95. http://dx.doi.org/10.1016/S1836-9553(12)70088-7

2. Costa LOP, Maher CG, Latimer J, Hodges PW, Herbert RD, Refshauge KM, McAuley JH, Jennings MD. Motor control exercise for chronic low back pain: a randomized placebocontrolled trial. Phys Ther. 2009;89(12):1275-1286. http://dx.doi.org/10.2522/ptj.20090218

3. García AN, Gondo FLB, Costa RA, Cyrillo FN, Silva TM, 
Costa LCM, et al. Effectiveness of the back school and Mckenzie techniques in patients with chronic non-specific low back pain: a protocol of a randomised controlled trial. BMC Musculoskeletal Disorders 2011;12: 179.

http://dx.doi.org/10.1186/1471-2474-12-179

4. González-Iglesias J, Fernández-de-Las-Pe-as C, Cleland J, Huijbregts P, Del Rosario Gutiérrez-Vega M. Short-Term Effects of Cervical Kinesio Taping on Pain and Cervical Range of Motion in Patients With Acute Whiplash Injury: A Randomized Clinical Trial. The Journal of Orthopaedic and Sports Physical Therapy 2009;39 (7):515-521. http://dx.doi.org/10.2519/jospt.2009.3072

5. Kase K, Wallis J, Kase T. Clinical Therapeutic Applications of the Kinesio Taping Method. 2003.

6. Karatas N, Bicici S, Baltaci G, Caner H. The effect of Kinesiotape application on functional performance in surgeons who have musculo skeletal pain after performing surgery. Turkish Neurosurgery 2012;22 (1): 83-89.

7. Marco Aurélio Nemitalla Added, Leonardo Oliveira Pena Costa, Thiago Yukio Fukuda, Diego Galace de Freitas, Evelyn Cassia Salomão, Renan Lima Monteiro and Lucíola da Cunha Menezes Costa. Efficacy of adding the kinesio taping method to guideline-endorsed conventional physiotherapy in patients with chronic nonspecific low back pain: a randomised controlled trial. BMC Musculoskeletal Disorders 2013;14-301.

8. Morris D, Jones D, Ryan H, Ryan CG. The clinical effects of Kinesio ${ }^{\circledR}$ Tex taping: A systematic review. Physiother Theory Pract 2013; 29(4):259-70. http://dx.doi.org/10.3109/09593985.2012.731675

9. Page P, Frank C, Lardner R. Assessment and Treatment of Muscle Imbalance: The Janda Approach 2010; 213-226.

10. Paoloni M, Bernetti A, Fratocchi G et al. Kinesio Taping applied to lumbar muscles influences clinical and electromyographic characteristics in chronic low back pain patients. European Journal of Physical and Rehabilitation Medicine 2011;47: 1-8.

11. Parreira Pdo C, Costa Lda C, Hespanhol LC Jr, Lopes AD, Costa LO. Current evidence does not support the use of Kinesio Taping in clinical practice: a systematic review. J Physiother 2014; 60(1):31-9.

http://dx.doi.org/10.1016/j.jphys.2013.12.008

12. Parreira Pdo C, Costa Lda C, Takahashi R, Hespanhol Junior LC, Luz Junior MA, Silva TM, Costa LO. Kinesio taping to generate skin convolutions is not better than sham taping for people with chronic non-specific low back pain: a randomised trial. J Physiother 2014;60(2):90-6.

http://dx.doi.org/10.1016/j.jphys.2014.05.003

13. Pelosin E, Avanzino L, Marchese R, Stramesi P, Bilanci M, Trompetto C, Abbruzzese G. kinesiotaping reduces pain and modulates sensory function in patients with focal dystonia: a randomized crossover pilot study. Neurorehabil Neural Repair 2013 Oct;27(8):722-31. http://dx.doi.org/10.1177/1545968313491010
14. Shaji John Kachanathu, Aqeel M. Alenazi, Hamada Eid Seif, Ashraf Ramadan Hafez, AbdulmohSen Meshari Alroumim. Comparison between Kinesio Taping and a Traditional Physical Therapy Program in Treatment of Nonspecific Low Back Pain. J. Phys. Ther. Sci 2014; 26: $1185-1188$. http://dx.doi.org/10.1589/jpts.26.1185

15. Tamburella F, Scivoletto G, Molinari M. Somatosensory inputs by application of KinesioTaping: effects on spasticity, balance, and gait in chronic spinal cord injury. Front Hum Neurosci 2014; 8:367. http://dx.doi.org/10.3389/fnhum.2014.00367

16. Thelen MD, Dauber JA, Stoneman PD. The clinical efficacy of kinesio tape for shoulder pain: a randomized, double-blinded, clinical trial. J Orthop Sports Phys Ther 2008; 38: 389-395. http://dx.doi.org/10.2519/jospt.2008.2791

17. ThiagoVilela Lemos, Kelice Cristina Pereira, Carina Celedonio Protássio, Lorrane Barbosa Lucas, Joao Paulo C. Matheus. The effect of Kinesio Taping on handgrip strength. J. Phys. Ther. Sci 2015;27: 567-570.

18. Yoshida A, Kahanov L. The Effect of Kinesio Taping on Lower Trunk Range of Motions. Research in Sports Medicine: An International Journal 2007;15 (2):103-112. http://dx.doi.org/10.1080/15438620701405206

\section{EFFECT OF KINESIO TAPING ON LOWER BACK PAIN AND SPINAL MOBILITY FOR MEN AND WOMEN} R. Bacevičienė, L. Janušonienė, M. Gintilienė

Key words: back pain, spinal mobility, kinesio taping. Summary

The most commonly occurring lower back pain is treated with an alternative method - kinesio taping. This method restores the correct muscle function, improves blood circulation and lymph flow, reduces pain by acting the physiological mechanisms, corrects joint position through proprioreception, restores the correct muscle function.

The aim was to determine the men's and women's pain and spinal mobility changes in lower back using kinesio taping. The study involved 10 patients aged $46.1 \pm 4.95$ years, who sufferers lower back pain. For all subjects radiological studies revealed L5-S1 intervertebral disk herniation. Pain was assessed every 4 hours by VAS scale and spine mobility before and after kinesio taping. Two $20 \mathrm{~cm}$ long and $5 \mathrm{~cm}$ wide K-Active strips were used for kinesio taping.

The results indicated that kinezio taping increased lower spine mobility - the impact on women was higher than in men; and reduced the pain in lower spine after 20 hours after kinesio taping. The most remarkable and the longest lasting pain reduction was observed in 44-56 hours; it was higher for women than for men.

Correspondence to: laurai.janusonienei@gmail.com

Gauta 2015-09-15 